\title{
Ultrasound and its clinical use in rheumatoid arthritis: where do we stand?
}

\author{
Aline Defaveri do Prado ${ }^{1,2^{*}}$, Henrique Luiz Staub², Melissa Cláudia Bisi² , Inês Guimarães da Silveira², \\ José Alexandre Mendonça ${ }^{3}$, Joaquim Polido-Pereira ${ }^{4,5}$ and João Eurico Fonseca ${ }^{4,5}$
}

\begin{abstract}
High-resolution musculoskeletal ultrasound (MSUS) has been increasingly employed in daily rheumatological practice and in clinical research. In rheumatoid arthritis (RA), MSUS can be now considered a complement to physical examination. This method evaluates synovitis through gray-scale and power Doppler and it is also able to identify bone erosions. The utilization of MSUS as a marker of RA activity has received attention in recent literature. Current data account for good correlation of MSUS with classical measures of clinical activity; in some instances, MSUS appears to perform even better. Diagnosis of subclinical synovitis by MSUS might help the physician in RA management. With some variation, interobserver MSUS agreement seems excellent for erosion and good for synovitis. However, lack of MSUS score standardization is still an unmet need. In this review, we describe several MSUS scores, as well as their correlation with clinical RA activity and response to therapy. Finally, we look at the relationship of MSUS with synovial tissue inflammation and discuss future perspectives for a better interpretation and integration of this imaging method into clinical practice.
\end{abstract}

Keywords: Musculoskeletal ultrasound, Gray-scale, Power Doppler, Cytokines, Rheumatoid arthritis

\section{Background}

Rheumatoid arthritis (RA) is a chronic inflammatory immune mediated disorder where synovial proliferation, pannus formation and bone erosions are histological hallmarks [1]. Proinflammatory cytokines play a major role in development of disease and clinical progression. Anti-cytokine therapy has brought a major impact in RA management [2].

Clinical assessment of RA patients includes history, physical examination, scores of disease activity and questionnaires addressing quality of life. As far as imaging is concerned, conventional radiograms and magnetic resonance imaging (MRI) are well-recognized support methods for clinical assessment and response to therapy. They have intrinsic problems, nevertheless. Radiograms cannot evaluate joint inflammation and show low sensitivity for

\footnotetext{
* Correspondence: adprado@gmail.com

${ }^{1}$ Rheumatology Unit, Nossa Senhora da Conceição Hospital, Porto Alegre, RS, Brazil

${ }^{2}$ Rheumatology Department, Sao Lucas Hospital, Faculty of Medicine of Pontifical Catholic University of Rio Grande do Sul (PUCRS), Av. Ipiranga, 6690/220, Porto Alegre 90610-000, Brazil

Full list of author information is available at the end of the article
}

damage; MRI, although sensitive, is expensive and not widely available $[1,2]$.

In recent years, high-resolution musculoskeletal ultrasound (MSUS) has been increasingly used in rheumatological practice worldwide [3]. While MSUS gray-scale (GS) usually identifies synovial proliferation, power Doppler $(\mathrm{pD})$ may recognize active inflammation and neoangiogenesis. Both parameters seem worthy of utilization in the follow-up of RA patients [4]. In addition, MSUS is also reliable for the detection of bone erosions [5] as well as for the detection of subclinical synovitis and prediction of disease relapse and structural progression [6].

Although unequivocally useful in RA, MSUS has intrinsic reproducibility issues that may be optimized through standardized training and recommendations. In 2010, a multinational group of 25 Rheumatologists from the American Continent participated in a consensus-based questionnaire and established the first recommendations and guidelines for MSUS course training in the Americas [7]. Besides, EULAR consensual advice for use of imaging techniques (MSUS included) in the management of RA has been recently proposed [8]. 
In this paper, we review the correlation of MSUS findings with synovial tissue inflammation in RA patients and its implications for a better clinical utilization of this imaging technique. Also, we discuss MSUS clinical application as compared to classical activity parameters. Lastly, we update MSUS techniques and interobserver reliability in RA.

\section{Ultrassound parameters and synovial tissue}

Comparison of MSUS findings with features of synovial tissue allows characterizing how far this technique can capture the inflammatory activity that is actually ongoing inside joints.

Andersen et al. studied the correlation between histological synovitis and GS and $\mathrm{pD}$ in RA patients and found fairly good correlations between $\mathrm{pD}$ and histological features of inflammation and proliferation, namely synovium expression of CD3, CD68, Ki67 and von Willebrand factor ( $\mathrm{r}$ between 0,44 and 0,57 ). There were areas of histological inflammation where no $\mathrm{pD}$ could be identified [9]. Other authors showed that 5 RA patients in DAS remission who had GS but negative $\mathrm{pD}$ had low likelihood of relapse after TNF inhibitor tapering and histologically had low infiltrates of macrophages (CD68+), T (CD3+) a B (CD20+) cells [10].

In a study of 14 RA patients in remission who were submitted to surgery, 15 synovial samples were collected. GS changes were found in $80 \%$ patients, $\mathrm{pD}$ detected in $60 \%$ of the individuals and MRI synovitis in $86 \%$. Histologically, 4 samples had severe inflammation, 6 moderate, 3 mild and 2 minimal [11].

In another study in 20 patients with knee arthritis, pD showed better correlation with histological synovitis than contrast-enhanced MRI [12]. In the setting of rheumatoid synovium, the thickness of synovial lining and the number of vessels are increased, although it is not clear whether the angiogenesis is a cause or a consequence of the inflammatory process $[13,14]$.

Koski et al. found that in RA synovium there was a good correlation between the number of vessels and the inflammatory state (synovium inflammatory infiltrate), but not with pD. They concluded that chronic histological synovitis was not always related with a positive $\mathrm{pD}$ [15] In fact, in another study by the same authors, $\mathrm{pD}$ was not always translating synovial inflammation and could be related with other pathologic processes, such as fibrosis [16]. Waltheret al found a correlation between the number of vessels and $\mathrm{pD}$, but did not report on the inflammatory state [17].

In healthy synovial joints, the presence of $\mathrm{pD}$ signal associated with serum levels of vascular endothelial growth factor (VEGF), but not with other growth factors or cytokines. This could support a role of VEGF in neo-angiogenesis in RA [18]. In a survey of 55 RA patients in clinical remission, pD correlated with VEGF levels and other angiogenesis markers [19]. On the contrary, a correlation between $\mathrm{pD}$ and serum vascular endothelium growth factor could not be established in RA patients according to a 2004 study [20].

Contrast-enhanced Doppler ultrasound may be superior to $\mathrm{pD}$ in translating a dynamic process such as synovitis in RA, in which perfusion may be determinant, but little is known about the correlation of these findings with histological features in the synovium RA. This method has proved to be superior to $\mathrm{pD}$ in defining active synovitis, using arthroscopy, but not MRI, as the gold standard [21-24].

Worthy of note, synovial production of IL-6 was found to associate with synovitis as detected by MRI and $\mathrm{pD}$ [25]. This in accordance with our own results, depicting that IL-6, but not other cytokines, correlated positively with DAS28, swollen joint count, 10-joint pD score and $\mathrm{GS} / \mathrm{pD}$ of both wrists. In multiple linear regression, the association of IL-6 with 10 -joint $\mathrm{pD}$ score was maintained even after adjustment for DAS28. There was no correlation of IL-6 with tender joint count, 10-joint GS score, or bone erosion [26].

Interestingly, Ball et al. described association of serum IL-6 with arthritis on physical examination and pD score in patients with systemic lupus erythematosus [27]. Overall, these findings $[26,27]$ may result from a prominent synovial production of IL-6. In fact, IL-6 stimulates angiogenesis [28], and this could eventually explain the association of IL- 6 concentrations with a positive $\mathrm{pD}$ in RA. A recent report accounted for association of serum IL-6 with MSUS parameters of synovitis in patients with early RA; of importance, serial measurements of IL-6 were linked to structural damage [29].

In patients with established RA, a correlation of serum IL-17 with synovial hypertrophy and $\mathrm{pD}$ in hand MSUS was documented [30]. Interestingly, the presence of Th-17 lymphocytes in synovial tissue was associated with a persistent pD signal, according to a 2010 study [31].

As seen, the study of the relationship of MSUS parameters with synovial tissue features is clearly a field open to research, which may add new pathogenic information and help to clarify MSUS usefulness in RA management.

\section{Correlation of MSUS with physical examination, inflammatory markers and patient reported outcomes}

For many years, Rheumatologists have been using the disease activity score of 28 joints (DAS28) and other composite scores as gold standard for assessment of RA activity; these tools have clearly brought great progress in treatment monitoring. Even though they are the most extensively validated methods for measuring disease activity to date [32], the precise way of objectively defining inflammation is still lacking. MSUS can be 
worthwhile in this context, since it is more sensitive than physical examination for detection of arthritis according to a number of studies [33-37].

In patients with joint inflammatory symptoms lasting less than 12 months, MSUS significantly increased the classification of patients as RA (31\% pretest, $61 \%$ post-test) [38]. In individuals with established RA, synovial hypertrophy and $\mathrm{pD}$ scores of wrists and MCP correlated significantly with physician-recorded clinical outcomes and helped the rheumatologist in clinical decision [39].

Of great importance, preliminary data indicated that the MSUS methodology improved the accuracy of the 2010 ACR/EULAR criteria for identifying patients needing methotrexate treatment. $\mathrm{GS} \geq 2$ and $\mathrm{pD} \geq 1$ were good indicators of synovitis [40].

According to a study published in 2001, pD scan of MCP joints was a reliable method in assessment of synovitis of RA patients, considering MRI as standard [41]. In a systematic review and metanalyis of 21 studies, MSUS was more effective than conventional radiograms for detection of bone erosions; efficacy was comparable to MRI and reproducibility was good [42]. In another systematic review, MSUS added value to clinical findings for the diagnosis of RA when studying at least MCP, wrist and MTP joints; to evaluate remission, scanning of at least wrist and MCP joints of the dominant side was advocated. In both circumstances, $\mathrm{pD}$ was a more reliable instrument as compared to GS [43].

Recent data suggested that both MSUS and clinical examination were relevant to appraise risk of subsequent structural damage in RA patients [44]. Subclinical joint inflammation detected by imaging techniques as MSUS probably accounts for the paradoxical structural deterioration seen in RA patients allegedly in clinical remission [45]. Of note, Peluso et al. demonstrated that remission as confirmed by $\mathrm{pD}$ was much more prevalent in patients with early than long-standing RA [46].

We have previously reported that $\mathrm{pD}, \mathrm{GS}$ and bone erosion on MSUS were associated with swollen joint count, but not with joint tenderness [47]. Concordance of physical examinationand MSUS assessment seems poor (not more than $50 \%$ between the most affected joint and $\mathrm{pD}$ signal), and RA structural progression has been more associated with swollen joint count than with pain [48-50].

Correlations studies of MSUS with disease activity are a matter of debate. In a study employing $\mathrm{pD}$ score of 22 joints and GS score of 28 joints, a defined correlation of MSUS parameters with classical measures of RA activity (acute phase proteins, DAS28) was found. Differently, correlation of MSUS scores with health assessment questionnaires were weak to moderate [51].
In a 2014 study, concordance level of standard activity measures with MSUS was evaluated. For such, a pD score of hands, radiocarpal and MTP joints was utilized. Discrepancies between pD and DAS28 occurred in 29\% of cases, promoting changes in therapeutic decision, in other words, supporting DMARD escalation in patients with continuing subclinical synovitis and preventing escalation in symptomatic patients without ultrasonographic synovitis [52]. Likewise, Gartner et al. demonstrated $\mathrm{pD}$ signal in up to $20 \%$ of patients in remission according to DAS28 [53].

Recently, it has been shown that the 7-joint GS/pD Backhaus score showed performance comparable to clinical and laboratory data in RA patients under various therapies. Higher score predicted bone erosions after one year. Of interest, Backhaus method was sensitive enough to demonstrate decline in bone erosions in patients who switched biological agents [54]. In patients in remission, a link of GS/pD positivity with risk of clinical flare and structural progression was demonstrated by metanalysis in 2014 [55].

A 2012 study revealed that the presence of $\mathrm{pD}$ signal was an accurate predictor of flare in RA patients in remission [56]. Synovitis detected by $\mathrm{pD}$ may predict biologic therapy tapering failure in RA patients in sustained remission, according to a very recent report [57]. Adding of $\mathrm{pD}$ was able to identify RA patients in DAS28 remission, with subclinically active disease. The same authors reported that the combination of clinical and $\mathrm{pD}$ parameters recognized patients in remission who could undergo anti-TNF dose tapering [58].

It has been observed that subclinical synovitis is long-lasting in RA patients in clinical remission [59]. In a study dated from 2012, pD, but not low-field MRI, predicted relapse and radiographic progression in RA patients with low levels of disease activity [60]. In early RA patients on conventional therapy, pD-positive synovial hypertrophy identified ongoing inflammation, even during remission and also predicted a short-term relapse [61].

In an observational study of 307 RA patients, Zufferey et al. demonstrated that many subjects in clinical remission according to classical parameters (DAS28 and ACR/ EULAR criteria) showed residual synovitis on GS and $\mathrm{pD}$ scan [62]. Yoshimi et al. documented synovitis by $\mathrm{pD}$ in patients in clinical inactivity and suggested that the $\mathrm{pD}$ parameter is essential to confirm "true remission" of RA [63].

Recently, a group of authors originally approached the correlation of MSUS with clinical scores in RA patients with and without fibromyalgia. While GS scores correlated with classical parameters in both groups, the $\mathrm{pD}$ analysis was more precise by correlating with clinical scores only in patients without fibromyalgia [64].

In 68 RA patients evaluated with a six-joint $\mathrm{pD}$ method (two MCP, wrists, knees), the global MSUS 
score correlated moderately with the DAS28; in this survey, $\mathrm{pD}$ positivity was a sensitive-to-change method for monitoring the short-term response to anti-TNF agents [65]. In a cross-sectional study of 97 RA patients, an inactive disease status defined by a 12 -joint $\mathrm{pD}$ score (but not clinical parameters) associated, interestingly, with decrease in complement levels in patients treated with biologics [66].

In 2015, the ARTIC trial addressed the question if MSUS could correlate with DAS28 defined RA remission criteria. In 238 patients with early RA randomized to perform or not GS/pD MSUS in addition to DAS28, both strategies (MSUS included or not) were effective to estimate remission after two years of therapy [67].

In summary, there has been plenty of recent literature looking at the role of MSUS either as a complement to physical examination or as a measure of disease activity. It seems the discrepancies between US findings and clinical findings on articular examination are more important in long standing RA and/or fibromyalgia associated RA patients, where metrics are less reliable (due to difficulties in physical examinations and on pain exacerbation). It remains an open question if MSUS would work as additional or preferential criteria for assessing RA activity. MSUS looks a promising instrument for monitoring RA disease activity, but a greater body of evidence still is required.

\section{Intra and interobserver agreement}

Another critical aspect when using MSUS in the evaluation of RA is reproductibility. Inter-reader analysis of the clinical assessment of joint inflammation can itself show some discrepancy [68, 69]. Intra and interobserver discrepancies in both acquisition of image and image interpretation have been a matter of concern.

A study dated from 2007 reported that the interobserver agreement of a 3-dimensional $\mathrm{pD}$ scan was better (>0.80) than a 2-dimensional quantitative $\mathrm{pD}$ method [70]. In healthy subjects, MSUS of MCP joints using an $18 \mathrm{MHz}$ transducer yielded an excellent interobserver kappa (0.83) for erosions [71]. A fair to good concordance (kappa 0.36-0.76) of a semiquantitative MCP score for cartilage damage was described in RA patients in 2010 [72].

Subclinical joint changes in asymptomatic feet of RA patients were recently assessed. Concordance between MSUS and radiograms was low (kappa 0.08-0.40). Inter-reader agreement was excellent for bone erosion (kappa =1), good for quantitative synovitis (0.64) and moderate (0.47) for $\mathrm{pD}$ signal [73].In 2011, the interobserver reliability of a synovitis MSUS resulted in moderate concordance (kappa 0.50) for quantification of synovitis in the radiocarpal joint [74].
Szkudlarek et al showed in thirty RA patients with active disease that MSUS agreement was good for erosions (kappa 0.78) and $\mathrm{pD}$ (0.72), and excellent for synovitis (0.81) evaluatingfive joints (second and third MCP, second PIP, first and second MTP) that were scanned by two experienced sonographers. [75]

The Swiss Sonography in Arthritis and Rheumatism (SONAR) group had previously developed a consistent MSUS method for assessing RA activity utilizing B-mode and pD scores [76]. The same group evaluated synovitis and erosion in six differentMSUS machines. Overall, agreement was not more than moderate. Considering only high-quality machines, kappa concordance was better for synovitis (0.64) than erosion (0.41) [77].

Yet in 2005, the EULAR promoted the "Train the trainers" course aiming to evaluate MSUS interobserver reliability in RA. Clinically dominant joint regions (shoulder, knee, ankle/toe, wrist/finger) were examined. Concordance was particularly high for bone lesions, bursitis, and tendon tears (kappa $=1)$. As a whole, interobserver concordance, sensitivities, and specificities were comparable with MRI [78].

The reliability of the Backhaus 7-joint score was evaluated in 2012 and the best interobserver concordance was obtained for bone erosions in second MTP (plantar side), with kappa of 1 . Agreement for $\mathrm{pD}$ in palmar side of wrist was good (0.79). Intraobserver reliability of the method was moderate to substantial [79].

In our own experience, we have been employing a 10-joint score exclusively of hand/wrist joints (dorsal aspects of wrists and second and third MCP, and volar aspect of second and third PIP joints of both hands). After evaluating 1380 joints of 60 RA patients, kappa agreement for synovitis ranged from fair to good (0.30-0.70); for cartilage changes, also from fair to good (0.28-0.63; for pD signal, from moderate to absolute agreement (0.53-1); and for erosions, from good to excellent (0.70-0.97) [80].

In 2014, the LUMINA European study assessed the reliability of grading MSUS videoclips with hand pathology in RA by employing non-sophisticated internet tools. Intra-reader concordance for $\mathrm{GS} / \mathrm{pD}$ synovitis was moderate to good $(0.52 / 0.62)$, while the interobserver agreement for global synovitis (synovitis and tenosynovitis) was not more than moderate (0.45) [81].

Also recently, a short collegiate consensus attempted to improve MSUS interobserver reliability. Concordance was good for B mode synovitis (0.75) and excellent for $\mathrm{pD}$ (0.88). Kappa values were excelllent for small hand joints, but poor to fair in wrists, elbows, ankles and MTP. Admittedly, the consensus meeting was useful to improve agreement in synovits scores of still images. Moreover, the consensus strongly emphasized 
the need for standards of image acquisition and interpretation [82].

The several studies [68-82] evaluating reliability of MSUS scores have revealed some variation. As a whole, MSUS seems very reliable for bone erosions (kappa ranging from good to excellent); in turn, the grade of agreement for synovitis, although generally moderate to good, has shown more fluctuation. Standardized training seems essential to improve all these outcomes.

\section{Ultrasound scores}

A high-resolution machine with a linear high-frequency probe $(7.5-18 \mathrm{MHz})$ should be utilized for evaluation of small joints. In the most widely used scoring systems, semiquantitative GS, generated in the B-mode, synovial proliferation is classified as: zero (absent); 1) mild (slight hipoechoic or anechoic image in articular capsule); 2) moderate (presence of elevation of articular capsule); 3) severe or marked (important distension of articular capsule). The semiquantitative scale of $\mathrm{pD}$ signal stratifies inflammatory activity and angiogenesis as follows: zero (absent); 1) mild (one pD signal); 2) moderate (two or more $\mathrm{pD}$ signal, meaning $<50 \%$ of intraarticular flow); 3) severe or marked (> 50\% of intraarticular flow) [83]. In addition, Carotti et al. reported that the resistive index (RI), using spectral Doppler, quantified inflammation in microvessels of finger joints and wrists and discriminated RA synovitis (higher values) from normal subjects [84]. Bone erosions, in turn, are defined according to the OMERACT criteria and are classified as present or absent [85]. Figure 1 illustrates MSUS findings in normal and RA hand joints.

There has been no agreement regarding which joints and tendons should be systematically examined in MSUS of RA patients. A number of different methods and scores have been advocated, without wide concordance to date. As a whole, it was proposed to include dorsal and volar exam of the hands in daily practice and clinical trials [33], but volar examination might not be consensual.

Historically, MSUS scores were firstly proposed in 2005 by two groups of authors $[83,86]$. Scheel et al. described different MCP and PIP scores for GS and pD [86]. In 2006, Loeuille et al. reported a 7-joint GS/pD score including wrist, MCP and MTP of dominant side [87]. One year later, an 8-joint system evaluating GS/pD of MCP and MTP of dominant side was proposed by Hensch et al. [88]. In 2008, Iagnocco et al. designed a 10-joint method including MCP, PIP, wrist and knee including tenosynovitis, bursitis and erosion in addition to GS/pD [89]. Also in 2008, a 12-joint simplified MSUS including elbow, wrist, MCP, knee and ankle was reported by Naredo [90].

The 7-joint MSUS score proposed by Backaus et al. in 2009 has been the most largely utilized in recent
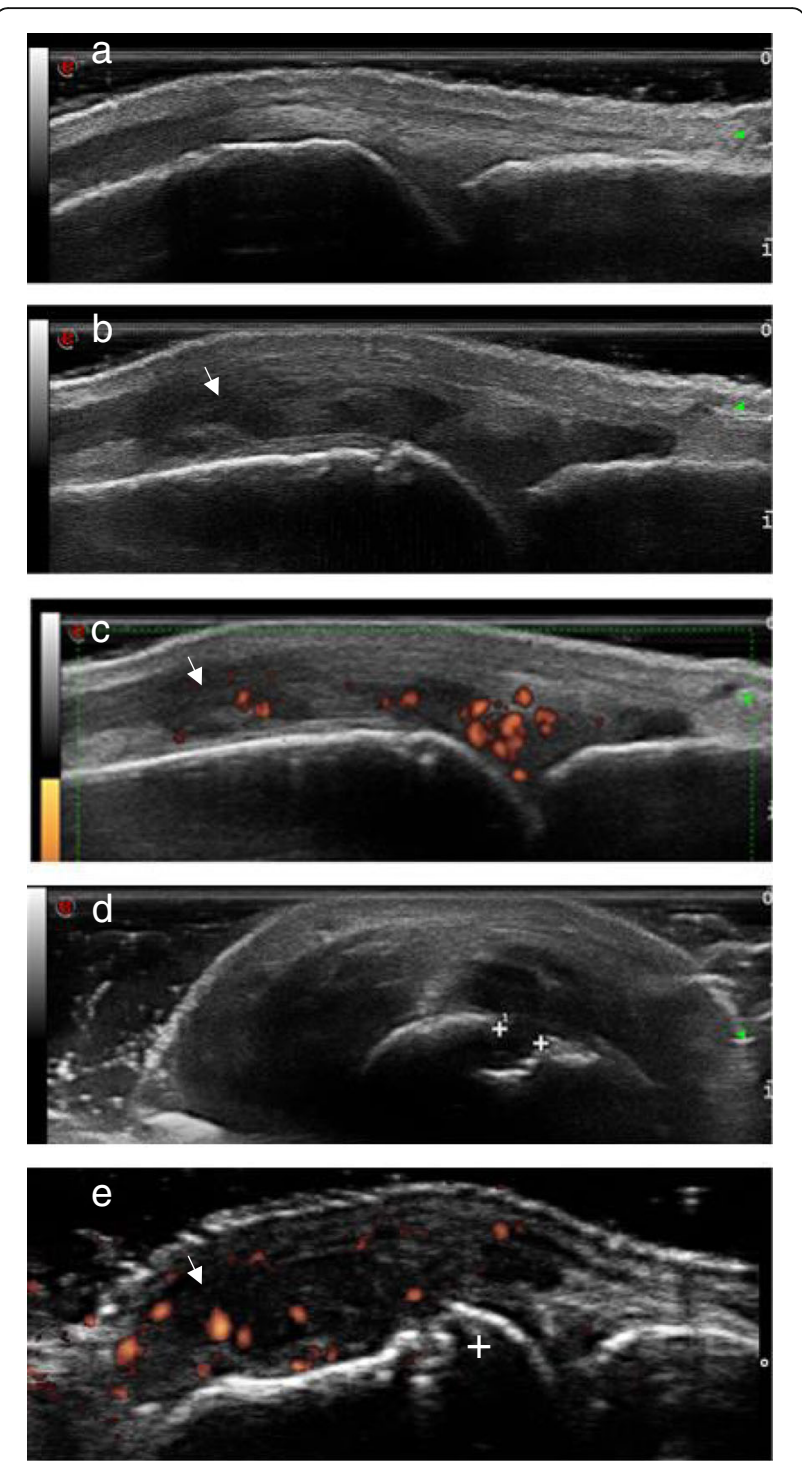

Fig. 1 Imagens of a normal MCP joint and an abnormal MCP joint of a RA patient. a Normal musculoskeletal ultrasound (MSUS) of third metacarpophalangeal (MCP) joint, longitudinal dorsal aspect; b Synovial proliferation grade 3 on second MCP, longitudinal dorsal aspect (arrow in hypoechoic area); c Synovial proliferation (arrow) and power Doppler (pD) captation grade 2 on second MCP, longitudinal dorsal aspect; $\mathbf{d}$ Interruption of cortical bone (erosion) on second MCP, radial aspect, longitudinal scan (plus sign); e MSUS of a patient with long-standing rheumatoid arthritis. Findings of second MCP (longitudinal dorsal aspect) include synovial proliferation grade 3 (arrow), pDcaptation grade 2 and bone erosion (plus sign)

literature and includes five hand and two foot joints of the clinically dominant side: wrist, second and third MCP and proximal interphalangeal (PIP), and second and fifth metatarsophalangeal (MTP) joints. This score also evaluated tenosynovitis and erosive changes [91].

In 2010, Hammer et al. proposed a 78-joint GS/pD score [92]. In 2012, a 6-joint MSUS score of wrists, 
MCP and knees utilized synovial effusion in conjunction with the synovial proliferation and $\mathrm{pD}$ parameters. This score was practical, trustworthy and sensitive-to-change for evaluating synovial inflammation in RA [93].

Of note, a semi-quantitative 10-joint score of synovial thickness and $\mathrm{pD}$ which included only MCP joints was proved a reliable endpoint in a clinical trial [94]. A modified 7-joint score adding dorsal and palmar recesses of the wrists, as well as of small joints of hands and feet, was described in 2014. In a survey of 32 patients with early RA (832 joints examined), GS and pD were sensitive to detect synovitis [95]. A total pD score of 8-joint (bilateral wrist, knee, and the second and third $\mathrm{MCP}$ joints), reported in 2015, was found to be a simple and effective tool for monitoring RA activity [96].

Also very recently, a 12 -joint score evaluating synovial hypertrophy by $\mathrm{B}$-mode technology and synovitis by $\mathrm{pD}$ signal was described. The wrist-hand-ankle-MTP assessments were able to predict unstable remission in RA patients presumably inactive on methotrexate therapy [97].

With such heterogeneity in the previously mentioned scores, it is important to verify if scores with low number of joints correlate well with scores involving more joints, in order to find a set feasible for clinical daily practice. For instance, the 7-joint Backaus score significantly correlated with a 12-joint instrument for monitoring of response to infliximab in RA patients, according to a 2016 study [98].

A novel GS/pD score composed of a bilateral approach of six hand joints (first, second and third MCP joints, second and third PIP joints and radiocarpal joint), two feet joints (second and third MTP) and, in addition, one tendon (extensor carpi ulnaris), performed better than previous scores in a longitudinal analysis [99]. Using a data-driven approach, the same group of authors set out to validate a new MSUS score in a large survey of early or established RA. The set comprising GS/pD scores of seven joints/two tendons (first and second MCP, second MCP, third PIP, radiocarpal, elbow, first and second MTP, tibialis posterior tendon, extensor carpi ulnaris tendon) preserved most of the information when compared to a 9-joint score (which added fifth MCP and fifth MTP) [100].

A systematic review of 14 studies published in 2011 did not yield a consensus as to the minimal number of joints to be included in a global MSUS score [101]. Newer recommendations after critical analysis of the most recent MSUS scores are expected. Table 1 lists, in chronological order, the MSUS scores described so far.

\section{Conclusion}

MSUS is an useful instrument to complement the physical examination of RA patients. The method is quick and safe. The GS/pD scales are helpful to detect early synovitis and MSUS is also sensitive in the identification of bone erosions.

The method is of interest to identify subclinical disease activity in patients considered to be in clinical remission and might add relevant information regarding response to therapy. Whether targeted therapy to $\mathrm{pD}$ activity would provide superior outcomes compared with treating to clinical targets alone, it is still a matter of open discussion, which was recently highlighted by the Targeted Ultrasound Initiative group [102]. Proper clinical trials are warranted to clarify this point.

Table 1 Musculoskeletal ultrasound scores described in chronological order

\begin{tabular}{|c|c|c|}
\hline Author/reference & Year & Joint characteristic/score elements \\
\hline Naredo et al. [83] & 2005 & 12-joint (wrists, MCP, PIP, knees); GS/pD \\
\hline Scheel et al. [86] & 2005 & Three different MCP/PIP scores; GS/pD \\
\hline Loeuille et al. [87] & 2006 & 7-joint (wrists, MCP, MTP); GS/pD \\
\hline Hensch et al. [88] & 2007 & 8-joint (MCP, MTP); GS/pD \\
\hline lagnocco et al. [89] & 2008 & 10-joint (MCP, PIP, wrist, knee); GS/pD, tenosynovitis, bursitis, erosion \\
\hline Naredo et al. [90] & 2008 & 12-joint (elbow, wrist, MCP, knee, ankle); GS/pD, tenosynovitis, bursitis \\
\hline Backhaus et al. [91] & 2009 & 7-joint (wrist, MCP, PIP, MTP); GS/pD, tenosynovitis, erosion \\
\hline Hammer et al. [92] & 2010 & 78-joint; GS/pD \\
\hline Perricone et al. [93] & 2012 & 6-joint (wrists, second MCP and knees); synovial effusion, GS/pD \\
\hline Seymour et al. [94] & 2012 & 10-joint (MCP); GS/pD \\
\hline Mendonça et al. [95] & 2014 & 7-joint (wrists, MCP, MTF); GS/pD \\
\hline Yoshimi et al. [96] & 2015 & 8-joint (wrists, knees, MCP); pD \\
\hline Aga A et al. [99] & 2015 & 6-joint (MCP, PIP,radiocarpal, MTP, extensor carpi ulnaris); GS/pD \\
\hline Aga A et al. [100] & 2015 & 7-joint/2 tendon (MCP, PIP, radiocarpal, elbow, MTP, tibialis posterior tendon, extensor carpi ulnaris tendon); GS/pD \\
\hline Janta I et al. [97] & 2016 & 12-joint (wrist, hand,ankle,MTP); B-mode, pD, tenosynovitis \\
\hline
\end{tabular}

GS gray scale, $p D$ power Doppler, MCP metacarpophalangeal joint, PIP proximal interphalangeal joint, MTP metatarsophalangeal joint 
Correlation of MSUS parameters with synovial tissue inflammatory activity and cytokines is also an area to be searched. Exploring this field may disclose new physiopathological features of synovitis and also better clarify the meaning of MSUS parameters.

Importantly, MSUS is practical, feasible and less expensive than MRI. Quality of MSUS devices is surely an item of major importance. Better training and competency of sonographers, allied to incorporation of modern ultrasound will certainly improve MSUS performance in the following years [103].

For the time being, a number of points regarding employment of MSUS in rheumatological daily practice demand elucidation. Validity and reproducibility of MSUS scores have still to be improved (interobserver concordance is yet variable - just like clinical assessment). Choice of equipment and selection of parameters to be utilized ( $\mathrm{pD}$ alone, $\mathrm{pD}$ plus GS, bone erosions, cartilage changes, synovial effusion, tenosynovitis, spectral Doppler) are also pending issues.

Since a pD signal can be also seen in healthy joints [104], the adding of spectral Doppler and estimate of RI might provide useful information regarding the flow in synovial membrane (low RI are seen in inflammed joints) [105]. New data on reliability of RI as a measure of synovial flow and microvessel inflammation should be available shortly.

Above all, MSUS score standardization, considering the particularities of each affected joint or tendon, is surely a requirement. Solved these questions, MSUS will consolidate its role as a reliable instrument to complement physical examination, appraise disease activity and monitor response to therapy in RA management.

\section{Key messages}

1) MSUS can be nowadays considered a complement to physical exam in patients with rheumatoid arthritis (RA).

2) MSUS seems to correlate well with indexes of disease activity in RA patients. Subclinical synovitis seen on MSUS could help the physician in clinical decisions.

3) Standardization of MSUS techniques is necessary to consolidate the method in clinical practice.

\footnotetext{
Abbreviations

ACR: American College of Rheumatology; DAS: Disease Activity Score; DAS28: Disease Activity Score in 28 joints; EULAR: Europena League Against Rheumatism; GS: gray scale; IL-17: interleukin 17; IL-6: interleukin 6; MCP: metacarpophangeal joint; MRI: magnetic resonance imaging; MSUS: musculoskeletal ultrasound; MTP: metatarsophalangeal joint; OMERACT: Outcome Measures in Rheumatology; pD: power Doppler; RA: rheumatoid arthritis; TNF: tumor necrosis factor; VEGF: vascular endothelial growth factor
}

\section{Authors' contributions}

AP, HS, JPP, IGS, JAM, MCB and JEF carried out literature search and reviewed the articles. AP and HS wrote the manuscript. JPP, IGS, JAM, MCB and JEF reviewed the manuscript and made adjustments to the text and contributed to update the review. All authors read and approved the final manuscript.

\section{Authors' information}

JAM is currently the chief of the "Image in Rheumatology" Committee of the Brazilian Society of Rheumatology.

AP and IGS teach rheumatology fellows on the use of ultrasound in

Rheumatology.

\section{Competing interests}

The authors declare that they have no competing interests.

\section{Publisher's Note}

Springer Nature remains neutral with regard to jurisdictional claims in published maps and institutional affiliations.

\section{Author details}

${ }^{1}$ Rheumatology Unit, Nossa Senhora da Conceição Hospital, Porto Alegre, RS, Brazil. ${ }^{2}$ Rheumatology Department, Sao Lucas Hospital, Faculty of Medicine of Pontifical Catholic University of Rio Grande do Sul (PUCRS), Av. Ipiranga, 6690/220, Porto Alegre 90610-000, Brazil. ${ }^{3}$ Rheumatology Unit, Pontifical Catholic University of Campinas (PUCCAMP), Campinas, SP, Brazil. ${ }^{4}$ Rheumatology Research Unit, Instituto de Medicina Molecular, Faculdade de Medicina, Universidade de Lisboa, Lisbon, Portugal. ${ }^{5}$ Rheumatology Department, Hospital de Santa Maria, Lisbon Academic Medical Centre, Lisbon, Portugal.

Received: 20 February 2018 Accepted: 16 July 2018

Published online: 02 August 2018

\section{References}

1. Scott D, Wolfe F, Huizinga T. Rheumatoid arthritis. Lancet. 2010;376:1094-108.

2. Mclnnes I, Schett G. Cytokines in the pathogenesis of rheumatoid arthritis. Nat Rev Immunol. 2007:7:429-42.

3. Ohrndorf S, Backhaus M. Pro musculoskeletal ultrasonography in rheumatoid arthritis. Clin Exp Rheumatol. 2015;33:S50-3.

4. Filippucci $E$, lagnocco A, Meenagh G. Ultrasound imaging for the rheumatologist. Clin Exp Rheumatol. 2006:24:1-5.

5. Zayat AS, Ellegaard $K$, Conaghan PG, Terslev L, EM a H, Freeston JE, et al. The specificity of ultrasound-detected bone erosions for rheumatoid arthritis. Ann Rheum Dis. 2015:74:897-903.

6. Iwamoto T, Ikeda K, Hosokawa J, Yamagata M, Tanaka S, Norimoto A, Sanayama $Y$, Nakagomi $D$, et al. Prediction of relapse after discontinuation of biologic agents by ultrasonographic assessment in patients with rheumatoid arthritis in clinical remission: high predictive values of total gray-scale and power Doppler scores that represent residual synovial. Arthritis Care Res. 2014;66:1576-81

7. Pineda C, Reginato AM, Flores V, Aliste M, Alva M, Aragón-Laínez RA, et al. Pan-American league of associations for rheumatology (PANLAR) recommendations and guidelines for musculoskeletal ultrasound training in the Americas for rheumatologists. J Clin Rheumatol. 2010;16:113-8.

8. Colebatch A, Edwards C, Østergaard M, van der Heijde D, Balint P, D'Agostino $M$, et al. EULAR recommendations for the use of imaging of the joints in the clinical management of rheumatoid arthritis. Ann Rheum Dis. 2013;72:804-14

9. Andersen M, Ellegaard K, Hebsgaard JB, Christensen R, Torp-Pedersen S, Kvist PH, et al. Ultrasound colour Doppler is associated with synovial pathology in biopsies from hand joints in rheumatoid arthritis patients: a cross-sectional study. Ann Rheum Dis. 2014;73:678-83.

10. Alivernini S, Peluso G, Fedele AL, Tolusso B, Gremese E, Ferraccioli G. Tapering and discontinuation of TNF-a blockers without disease relapse using ultrasonography as a tool to identify patients with rheumatoid arthritis in clinical and histological remission. Arthritis Res Ther. 2016;18:39

11. Anandarajah A, Thiele R, Giampoli E, Monu J, Seo GS, Feng C, et al. Patients with rheumatoid arthritis in clinical remission manifest persistent joint inflammation on histology and imaging studies. J Rheumatol. 2014;41:2153-60

12. Takase $K$, Ohno S, Takeno M, Hama M, Kirino Y, Ihata A, et al. Simultaneous evaluation of long-lasting knee synovitis in patients undergoing arthroplasty 
by power Dopplerultrasonography and contrast-enhanced MRI in comparison with histopathology. Clin Exp Rheumatol. 2012;30:85-92.

13. Koski J. Doppler Imaging and Histology of the Synovium. J Rheumatol. 2012;39:452-3

14. Paleolog EM. The vasculature in rheumatoid arthritis: cause or consequence? Int J Exp Pathol. 2009;90:249-61.

15. Koski JM, Saarakkala S, Helle M, Hakulinen U, Heikkinen JO, Hermunen H. Power Doppler ultrasonography and synovitis: correlating ultrasound imaging with histopathological findings and evaluating the performance of ultrasound equipments. Ann Rheum Dis. 2006;65:1590-5.

16. Koski JM, Saarakkala S, Helle M, Hakulinen U, Heikkinen JO, Hermunen $\mathrm{H}$, et al. Assessing the intra- and inter-reader reliability of dynamic ultrasound images in power Doppler ultrasonography. Ann Rheum Dis. 2006;65:1658-60.

17. Walther M, Harms H, Krenn V, Radke S, Faehndrich TP, Gohlke F. Correlation of power Doppler sonography with vascularity of the synovial tissue of the knee joint in patients with osteoarthritis and rheumatoid arthritis. Arthritis Rheum. 2001;44:331-8.

18. Kitchen J, Kane D. Greyscale and power Doppler ultrasonographic evaluation of normal synovial joints: correlation with pro- and antiinflammatory cytokines and angiogenic factors. Rheumatology (Oxford). 2015;54:458-62.

19. Ramirez J, Ruiz-Esquide V, Pomes I, Celis R, Cuervo A, Hernandez M, et al. Patients with rheumatoid arthritis in clinical remission and ultrasounddefined active synovitis exhibit higher disease activity and incresed serum levels of angiogenic biomarkers. Arthritis Res Ther. 2014;16:R5.

20. Strunk J, Heineman E, Neeck G, Schmidt KL, Lange U. A new approach to studying angiogenesis in rheumatoid arthritis by means of power Doppler ultrasonography and measurement of serum vascular endothelial growth factor. Rheumatology. 2004;43:1480-3.

21. Terslev L, Torp-Pedersen S, Bang N, Koenig MJ, Nielsen MB, Bliddal H. Doppler ultrasound findings in healthy wrists and finger joints before and after use of two different contrast agents. Ann Rheum Dis. 2005;64:824-7.

22. Klauser A, Frauscher F, Schirmer M, Halpern E, Pallwein L, Herold M, et al. The value of contrast-enhanced color Doppler ultrasound in the detection of vascularization of finger joints in patients with rheumatoid arthritis. Arthritis Rheum. 2002;46:647-53.

23. Fiocco U, Ferro F, Cozzi L, Vezzù M, Sfriso P, Checchetto C, et al. Contrast medium in power Doppler ultrasound for assessment of synovial vascularity: comparison with arthroscopy. J Rheumatol. 2003;30:2170-6.

24. Szkudlarek M, Court-Payen M, Strandberg C, Klarlund M, Klausen T, Østergaard M. Contrast-enhanced power Doppler ultrasonography of the metacarpophalangeal joints in rheumatoid arthritis. Eur Radiol. 2003;13:163-8.

25. Andersen M, Boesen M, Ellegaard K, Christensen R, Söderström K, Søe N, et al. Synovial explant inflammatory mediator production corresponds to rheumatoid arthritis imaging hallmarks: a cross-sectional study. Arthritis Res Ther. 2014;16:R107.

26. Do Prado AD, Bisi MC, Piovesan DM, Bredemeier M, Batista TS, Petersen $L$, et al. Ultrasound power Doppler synovitis is associated with plasma IL-6 in established rheumatoid arthritis. Cytokine. 2016;83:27-32.

27. Ball E, Gibson D, Rooney AB. Plasma IL-6 levels correlate with clinical and ultrasound measures of arthritis in patients with systemic lupus erythematosus. Lupus. 2014;23:46-56.

28. Brzustewicz E, Bryl E. The role of cytokines in the pathogenesis of rheumatoid arthritis. Practical and potential application of cytokines as biomarkers and targets of personalized therapy. Cytokine. 2015;76:527-36.

29. Baillet A, Gossec L, Paternotte L, Paternotte S, Etcheto A, Combe B, et al. Evaluation of serum Interleukin-6 level as a surrogate marker of synovial inflammation and as a factor of structural progression in early rheumatoid arthritis: results from a French National Multicenter Cohort. Arthritis Care Res (Hoboken). 2015;67:905-12.

30. Fazaa A, Ben Abdelghani K, Abdeladhim M, Laatar A, Ben Ahmed M, Zakraoui L. The level of interleukin-17 in serum is linked to synovial hypervascularization in rheumatoid arthritis. Jt Bone Spine. 2014;81:550-1.

31. Gullick N, Evans H, Church L, Javaraj D, Filer A. Linking power Doppler ultrasound to the presence of Th17 cells in the rheumatoid. PLoS One. 2010;5:e12516

32. Van der Heijde D, van 't Hof M, van Riel P, Theunisse L, Lubberts $E$, van Leeuwen $\mathrm{M}$, et al. Judging disease activity in clinical practice in rheumatoid arthritis: first step in the development of a disease activity score. Ann Rheum Dis. 1990;49:916-20.
33. Vlad V, Berghea F, Libianu S, Balanescu A, Bojinca V, Constantinescu C, Abobului M, Predeteanu D, Ionescu R. Ultrasound in rheumatoid arthritis: volar versus dorsal synovitis evaluation and scoring. BMC Musculoskelet Disord. 2011;12:124.

34. Szkudlarek M, Narvestad E, Klarlund M, Court-Payen M, Thomsen HS, Østergaard M. Ultrasonography of the metatarsophalangeal joints in rheumatoid arthritis: comparison with magnetic resonance imaging, conventional radiography, and clinical examination. Arthritis Rheum. 2004; 50:2103-12.

35. Salaffi F, Filippucci E, Carotti M, Naredo E, Meenagh G, Ciapetti A, et al. Interobserver agreement of standard joint counts in early rheumatoid arthritis: a comparison with grey scale ultrasonography - a preliminary study. Rheumatology (Oxford). 2008;47:54-8.

36. Ogishima H, Tsuboi H, Umeda N, Horikoshi M, Kondo Y, Sugihara M. Analysis of subclinical synovitis detected by ultrasonography and low-field magnetic resonance imaging in patients with rheumatoid arthritis. Mod Rheumatol. 2014:24:60-8.

37. Mendonca J, Yazbek M, Laurindo I, Bertolo M. Wrist ultrasound analysis of patients with early rheumatoid arthritis. Braz J Med Biol Res. 2011:44:11-5.

38. Rezaei H, Torp-Pedersen S, af Klint E, Backheden M, Kisten Y, Gyori N, et al. Diagnostic utility of musculoskeletal ultrasound in patients with suspected arthritis - a probabilistic approach. Arthritis Res Ther. 2014;16:448-55.

39. Ceponis A, Onishi M, Bluestein H, Kalunian K, Townsend J, Kavanaugh A. Utility of the ultrasound examination of the hand and wrist joints in the management of established rheumatoid arthritis. Arthritis Care Res. 2014;66:236-44

40. Nakagomi D, Ikeda K, Okubo A, Iwamoto T, Sanayama Y, Takahashi K, et al. Ultrasound can improve the accuracy of the 2010 American College of Rheumatology/European league against rheumatism classification criteria for rheumatoid arthritis to predict the requirement for methotrexate treatment. Arthritis Rheum. 2013;65:890-8.

41. Szkudlarek M, Court-Payen M, Strandberg C, Klarlund M, Klausen T, Ostergaard M. Power Doppler ultrasonography for assessment of synovitis in the metacarpophalangeal joints of patients with rheumatoid arthritis: a comparison with dynamic magnetic resonance imaging. Arthritis Rheum. 2001:44:2018-23.

42. Baillet A, Gaujoux-Viala C, Mouterde G, Pham T, Tebib J, Saraux A, Fautrel B, Cantagrel A, Le Loët X, Gaudin P. Comparison of the efficacy of sonography, magnetic resonance imaging and conventional radiography for the detection of bone erosions in rheumatoid arthritis patients: a systematic review and meta-analysis. Rheumatology (Oxford). 2011;50:1137-47.

43. Ten Cate DF, Luime JJ, Swen N, Gerards AH, De Jager MH, Basoski NM. Role of ultrasonography in diagnosing early rheumatoid arthritis and remission of rheumatoid arthritis - a systematic review of the literature. Arthritis Res Ther. 2013;15:R4

44. Dougados M, DEvauchelle-Pensec V, Ferlet J, Jousse-Joulin S, D'Agostino M, Backhaus M. The ability of synovitis to predict structural damage in rheumatoid arthritis: a comparative study between clinical examination and ultrasound. Ann Rheum Dis. 2013;72:665-71.

45. Brown A, Conaghan P, Karim Z, Quinn M, Ikeda K, Peterfy C, et al. An explanation for the apparent dissociation between clinical remission and continued structural deterioration in rheumatoid arthritis. Arthritis Rheum. 2008:58:2958-67.

46. Peluso G, Michelutti A, Bosello S, Gremese E, Toluso B, Ferraccioli G. Clinical and ultrasonographic remission determines different changes of relapse in early and long standing rheumatoid arthritis. Ann Rheum Dis. 2011;70:172-5.

47. Do Prado AD, Bisi M, Piovesan D, Bredemeieir M, Silveira I, Mendonça J, et al. Association of clinical examination with gray scale and power Doppler ultrassonography in established rheumatoid arthritis. J Clin Rheumatol. 2016; in press

48. Yoshimi R, Toyota Y, Tsuchida N, Sugiyama Y, Kunishita Y, Kishimoto D, et al. Considerable discrepancy between Patient's assessment and ultrasonography assessment on the most affected joint in rheumatoid arthritis [abstract]. Arthritis Rheumatol. 2015;67:S10.

49. Filer A, de Pablo P, Allen G, Nightingale P, Jordan A, Jobanputra P. Utility of ultrasound joint counts in the prediction of rheumatoid arthritis in patients with very early synovitis. Ann Rheum Dis. 2011;70:500-7.

50. Smolen J, Van Der Heijde D, St Clair E, Emery P, Bathon J, Keystone E, et al. Predictors of joint damage in patients with early rheumatoid arthritis treated with high-dose methotrexate with or without concomitant infliximab: results from the ASPIRE trial. Arthritis Rheum. 2006;54:702-10. 
51. Damjanov N, Radunovic G, Prodanovic S, Vukovic V, Milic V, SimicPasalic K. Construct validity and reliability of ultrasound disease activity score in assessing joint inflammation in RA: comparison with DAS-28. Rheumatology (Oxford). 2012:51:120-8.

52. Dale J, Purves D, McConnachie A, McInnes I, Porter D. Tightening up? Impact of musculoskeletal ultrasound disease activity assessment on early rheumatoid arthritis patients treated using a treat to target strategy. Arthritis Care Res. 2014;66:19-26.

53. Gärtner M, Mandl P, Radner H, Supp G, Machold K, Aletaha D, et al. Sonographic joint assessment in rheumatoid arthritis: associations with clinical joint assessment during a state of remission. Arthritis Rheum. 2013; 65:2005-14.

54. Backhaus T, Ohrndorf S, Kellner H, Strunk J, Hartung W, Sattler H, et al. The US7 score is sensitive to change in a large cohort of patients with rheumatoid arthritis over 12 months of therapy. Ann Rheum Dis. 2013;72:1163-9.

55. Nguyen H, Ruyssen-Witrand A, Gandjbakhch F, Constantin A, Foltz V, Cantagrel A. Prevalence of ultrasound-detected residual synovitis and risk of relapse and structural progression in rheumatoid arthritis patients in clinical remission: a systematic review and meta-analysis. Rheumatology. 2014;53:2110-8.

56. Saleem B, Brown A, Quinn M, Karim Z, Hensor E, Conaghan P, et al. Can flare be predicted in DMARD treated RA patients in remission, and is it important? A cohort study. Ann Rheum Dis. 2012;71:1316-21.

57. Naredo E, Valor L, De la Torre I, Montoro M, Bello N, Martinez-Barrio J, et al. Predictive value of Doppler ultrasound-detected synovitis in relation to failed tapering of biologic therapy in patients with rheumatoid arthritis. Rheumatology. 2015;54:1408-14.

58. Marks J, Holroyd C, Dimitrov B, Armstrong R, Calogeras A, Cooper C, et al. Does combined clinical and ultrasound assessment allow selection of individuals with rheumatoid arthritis for susteined reduction of anti-tumor necrosis factor therapy? Arthritis Care Res. 2015;67:746-53.

59. Gärtner M, Alasti F, Supp G, Mandl P, Smolen J, Aletaha D. Persistence of subclinical sonographic joint activity in rheumatoid arthritis in sustained clinical remission. Ann Rheum Dis. 2015;74:2050-3.

60. Foltz V, Gandjbakhch F, Etchepare F, Rosenberg C, Tanguy M, Rozenberg S, et al. Power Doppler ultrasound, but not low-field magnetic resonance imaging, predicts relapse and radiographic disease progression in rheumatoid arthritis patients with low levels of disease activity. Arthritis Rheum. 2012;64:67-76.

61. Scirè C, Montecucco C, Codullo V, Epis O, Todoerti M, Caporali R. Ultrasonographic evaluation of joint involvement in early rheumatoid arthritis in clinical remission: power Doppler signal predicts short-term relapse. Rheumatol. 2009:48:1092-7.

62. Zufferey P, Möller B, Brulhart L, Tamborrini G, Scherer A, Finckh A, et al. Persistence of ultrasound synovitis in patients with rheumatoid arthritis fulfilling the DAS28 and/or the new ACR/EULAR RA remission definitions: results of an observational cohort study. Joint Bone Spine. 2014;81:426-32.

63. Yoshimi R, Hama M, Takase K, Ihata A, Kishimoto D, Terauchi K, et al. Ultrasonography is a potent tool for the prediction of progressive joint destruction during clinical remission of rheumatoid arthritis. Mod Rheumatol. 2013;23:456-65.

64. da Silva Chakr RM, Brenol JC, Behar M, Mendonça JA, Kohem CL, Monticielo $\mathrm{OA}$, et al. Is ultrasound a better target than clinical disease activity scores in rheumatoid arthritis with fibromyalgia? A case-control study. PLoS One. 2015;10:e0118620.

65. lagnocco A, Finucci A, Ceccarelli F, Perricone C, lorgoveanu V, Valesini G Power Doppler ultrasound monitoring of response to anti-tumour necrosis factor alpha treatment in patients with rheumatoid arthritis. Rheumatology (Oxford). 2015;54:1890-6.

66. Montoro Alvarez M, Chong OY, Janta I, González C, López-Longo J, Monteagudo I, Valor L, et al. Relation of Doppler ultrasound synovitis versus clinical synovitis with changes in native complement component levels in rheumatoid arthritis patients treated with biologic disease-modifying antirheumatic drugs. Clin Exp Rheumatol. 2015;33:141-5.

67. Haavardsholm E, Aga A, Olsen I, Hammer H, Uhlig T, Fremstad H, et al. Aiming for remission in rheumatoid arthritis: clinical and radiographic outcomes from a randomized controlled strategy trial investigating the added value of ultrasonography in a treat-to-target regimen [abstract]. Arthritis Rheumatol. 2015:67:S10.

68. Hart LE, Tugwell P, Buchanan WW, Norman GR, Grace EM, Southwell D. Grading of tenderness as a source of interrater error in the Ritchie articular index. J Rheumatol. 1985;12:716-7.
69. Thompson PW, Hart LE, Goldsmith CH, Spector TD, Bell MJ, Ramsden MF. Comparison of four articular indices for use in clinical trials in rheumatoid arthritis: patient, order and observer variation. J Rheumatol. 1991;18:661-5.

70. Strunk J, Strube K, Rumbaur C, Lange U, Müller-Ladner U. Interobserver agreement in two- and three-dimensional power Doppler sonographic assessment of synovial vascularity during anti-inflammatory treatment in patients with rheumatoid arthritis. Ultraschall Med. 2007;28:409-15.

71. Fodor D, Felea I, Popescu D, Motei A, Ene P, Serban O, Micu M. Ultrasonography of the metacarpophalangeal joints in healthy subjects using an $18 \mathrm{MHz}$ transducer. Med Ultrason. 2015;17:185-91.

72. Filippucci E, da Luz KR, Di Geso L, Salaffi F, Tardella M, Carotti M, et al. Interobserver reliability of ultrasonography in the assessment of cartilage damage in rheumatoid arthritis. Ann Rheum Dis. 2010;69:1845-8.

73. Sant'Ana Petterle G, Natour J, Rodrigues da Luz K, Soares Machado F, dos Santos MF, da Rocha Correa Fernandes A, et al. Usefulness of US to show subclinical joint abnormalities in asymptomatic feet of RA patients compared to healthy controls. Clin Exp Rheumatol. 2013;31:904-12.

74. Luz KR, Furtado R, Mitraud SV, Porglhof J, Nunes C, Fernandes AR, Natour J. Interobserver reliability in ultrasound assessment of rheumatoid wrist joints. ActaReumatol Port. 2011;36:245-50.

75. Szkudlarek M, Court-Payen M, Jacobsen S, Klarlund M, Thomsen HS, Østergaard M. Interobserver agreement in ultrasonography of the finger and toe joints in rheumatoid arthritis. Arthritis Rheum. 2003;48:955-62.

76. Zufferey P, Brulhart L, Tamborrini G, Finckh A, Scherer A, Moller B, et al. Ultrasound evaluation of synovitis in RA: correlation with clinical disease activity and sensitivity to change in an observational cohort study. Jt Bone Spine. 2014;81:222-7.

77. Brulhart L, Ziswiler HR, Tamborrini G, Zufferey P, SONAR/SCQM programmes. The importance of sonographer experience and machine quality with regards to the role of musculoskeletal ultrasound in routine care of rheumatoid arthritis patients. Clin Exp Rheumatol. 2015;33:98-101.

78. Scheel AK, Schmidt WA, Hermann KG, Bruyn GA, D'Agostino MA, Grassi W, et al. Interobserver reliability of rheumatologists performing musculoskeletal ultrasonography: results from a EULAR "train the trainers" course. Ann Rheum Dis. 2005;64:1043-9.

79. Ohrndorf S, Fischer IU, Kellner H, Strunk J, Hartung W, Reiche B, et al. Reliability of the novel 7-joint ultrasound score: results from an inter- and intraobserver study performed by rheumatologists. Arthritis Care Res (Hoboken). 2012;64:1238-43.

80. Bisi M, do Prado A, Rabelo C, Brollo F, da Silveira I, JA M, et al. Articular ultrasonography: interobserver reliability in rheumatoid arthritis. Rev Bras Reumatol. 2014:54:250-4.

81. Vlad V, Berghea F, lagnocco A, Micu M, Damjanov N, Skakic V, et al. Inter \& intra-observer reliability of grading ultrasound videoclips with hand pathology in rheumatoid arthritis by using non- sophisticated internet tools (LUMINA study). Med Ultrason. 2014;16:32-6.

82. Cheung PP, Kong KO, Chew LC, Chia FL, Law WG, Lian TY, Tan YK, Cheng YK. Achieving consensus in ultrasonography synovitis scoring in rheumatoid arthritis. Int J Rheum Dis. 2014;17:776-81.

83. Naredo E, Bonilla G, Gamero F, Uson J, Carmona L, Laffon A. Assessment of inflammatory activity in rheumatoid arthritis: a comparative study of clinical evaluation with grey scale and power Doppler ultrassonography. Ann Rheum Dis. 2005;64:375-81.

84. Carotti M, Salaffi F, Morbiducci J, Ciapetti A, Bartolucci L, Gasparini S, et al. Colour Doppler ultrasonography evaluation of vascularization in the wrist and finger joints in rheumatoid arthritis patients and healthy subjects. Eur J Radiol. 2012;81:1834-8

85. Wakefield R, Balint P, Szkudlarek M, Fillipucci E, Backhaus M, D'Agostino M OMERACT 7 Special Interest Group. Musculoskeletal ultrasound including definitions for ultrasonographic pathology. J Rheumatol. 2005;32:2485-7.

86. Scheel AK, Hermann KG, Kahler E, et al. A novel ultrasonografic synovitis scoring system suitable for analyzing finger joint inflammation in rheumatoid arthritis. Arthritis Rheum. 2005;52:733-43.

87. Loeuille D, Sommier JP. ScUSI, an ultrasound inflammatory score, predicts sharp progression at 7 months in RA patients. Arthritis Rheum. 2006;54:S139.

88. Hensch A, Hermann KG. Impact of B mode, power Doppler and contrast enhanced ultrasonography in RA patients on anti-TNF alfa therapy. Arthritis Rheum. 2007;56:S280.

89. lagnocco A, Filippucci E, Perella C, Ceccarelli F, Cassarà E, Alessandri C, et al. Clinical and ultrasonographic monitoring of response to adalimumabe treatment in rheumatoid arthritis. J Rheumatol. 2008;35:35-40. 
90. Naredo E, Rodríguez M, Campos C, Rodríguez-Heredia JM, Medina JA, Giner E, Martínez O, et al. Validity, reproducibility, and responsiveness of a twelvejoint simplified power dopplerultrasonographic assessment of joint inflammation in rheumatoid arthritis. Arthritis Rheum. 2008:59:515-22.

91. Backhaus M, Ohrndorf S, Kellner H, Strunk J, Backhaus T, Hartung W. Evaluation of a novel 7-joint ultrasound score in daily rheumatologic practise: a pilot project. Arthritis Rheum. 2009;61:1194-201.

92. Hammer HB, Sveinsson M, Kongtorp AK, Kvien TK. A 78-joints ultrasonographic assessment is associated with clinical assessments and is highly responsive to improvement in a longitudinal study of patients with rheumatoid arthritis starting adalimumab treatment. Ann Rheum Dis. 2010;69:1349-51.

93. Perricone C, Ceccarelli F, Modesti M, Vavala C, Di Franco M, Valesini G, lagnocco A. The 6-joint ultrasonographic assessment: a valid, sensitive-tochange and feasible method for evaluating joint inflammation in RA. Rheumatology (Oxford). 2012;51:866-73.

94. Seymour M, Pétavy F, Chiesa F, Perry H, Lukey PT, Binks M, et al. Ultrasonographic measures of synovitis in an early phase clinical trial: a double-blind, randomized, placebo and comparator controlled phase lla trial of GW274150 (a selective inducible nitric oxide synthase inhibitor in rheumatoid arthritis. Clin Exp Rheumatol. 2012;30:254-61.

95. Mendonça JA, Yazbek MA, Costallat BL, Gutiérrez M, Bértolo MB. The modified US7 score in the assessment of synovitis in early rheumatoid arthritis. Rev Bras Reumatol. 2014;54:287-94.

96. Yoshimi R, lhata A, Kunishita Y, Kishimoto D, Kamiyama R, Minegishi K, et al. A novel 8-joint ultrasound score is useful in daily practice for rheumatoid arthritis. Mod Rheumatol. 2015:25:379-85.

97. Janta I, Valor L, De la Torre I, MartínezEstupiñán L, Nieto JC, Ovalles-Bonilla $J G$, et al. Ultrasound-detected activity in rheumatoid arthritis on methotrexate therapy: which joints and tendons should be assessed to predict unstable remission? Rheumatol Int. 2016;36:387-96.

98. Leng X, Xiao W, Xu Z, Zhu X, Liu Y, Zhao D, et al. Ultrasound7 versus ultrasound 12 in monitoring the response to infliximab in patients with rheumatoid arthritis. Clin Rheumatol. 2016;35:587-95.

99. Aga A, Lie E, Olsen I, Hammer H, Uhlig T, van der Heijde D, et al. Development of an ultrasound joint inflammation score for rheumatoid arthritis through a data-driven approach. Arthritis Rheumatol. 2015;67:S10.

100. Aga $A B$, Hammer $H B$, Olsen IC, Uhlig $T$, Kvien TK, van der Heijde $D$, et al. First step in the development of an ultrasound joint inflammation score for rheumatoid arthritis using a data-driven approach. Ann Rheum Dis. 2016;75:1444-51.

101. Mandl P, Naredo E, Wakefield R, Conaghan P, D'Agostino M, OMERACT Ultrasound Task Force, et al. A systematic literature review analysis of ultrasound joint count and scoring systems to assess synovitis in rheumatoid arthritis according to the OMERACT filter. J Rheumatol. 2011;38:2055-62.

102. Wakefield RJ, D'Agostino MA, Naredo E, Buch MH, lagnocco A, Terslev L, et al. After treat-to-target: can a targeted ultrasound initiative improve RA outcomes? Ann Rheum Dis. 2012;71:799-803.

103. Gutierrez M, Okano T, Reginato AM, Cazenave T, Ventura-Rios L, Bertolazzi C, Pineda C. Pan-American League Against Rheumatisms (PANLAR) Ultrasound Study Group. New Ultrasound Modalities in Rheumatology. J Clin Rheumatol. 2015;21:427-34.

104. Terslev L, Torp-Pedersen E, Qvistgaard E, von der Recke P, Bliddal H. Doppler ultrasound findings in healthy wrists and finger joints. Ann Rheum Dis. 2004;63:644-8.

105. Vlad V, Micu M, Porta F, Radunovic G, Nestorova R, Petranova T, et al. Ultrasound of the hand and wrist in rheumatology. Med Ultrason. 2012;14:42-8.

\section{Ready to submit your research? Choose BMC and benefit from}

- fast, convenient online submission

- thorough peer review by experienced researchers in your field

- rapid publication on acceptance

- support for research data, including large and complex data types

- gold Open Access which fosters wider collaboration and increased citations

- maximum visibility for your research: over $100 \mathrm{M}$ website views per year

At $\mathrm{BMC}$, research is always in progress.

Learn more biomedcentral.com/submissions 